\title{
Value chain analysis as a proposed method to link dog trading with rabies in Nusa Tenggara Islands
}

\author{
Dikky Indrawan \\ School of Business \\ IPB University (Bogor Agricultural \\ University) \\ Bogor, Indonesia \\ rdikky@apps.ipb.ac.id
}

\author{
Syafrison Idris \\ Sub Directorate of Disease \\ Surveillance, Directorate of Animal \\ Health \\ Ministry of Agriculture Indonesia \\ syafrisoni@gmail.com
}

\author{
Etih Sudarnika \\ Department of Animal Disease and \\ Veterinary Public Health, Faculty of \\ Veterinary Medicine \\ IPB University (Bogor Agricultural \\ University) \\ Bogor, Indonesia \\ etih@apps.ipb.ac.id
}

\author{
Henk Hogeveen \\ Business Economics Group \\ Wageningen University \& Research \\ Wageningen, The Netherlands \\ henk.hogeveen@wur.nl
}

\begin{abstract}
In early 2019, rabies outbreak in Dompu, West Nusa Tenggara killed five people and 527 people were bitten in the last six months. Since this area was declared as rabiesfree zone, it is suggested that there were many possible entrances of a dog by trading activities. The objective of this paper was to propose a method to study a dog trade between islands that may contribute to a rabies outbreak. Value chain analysis was proposed to structure the in-depth interview and analyzed the results. The chain governance was defined based on the dog trade activity to explain the transaction among actors. The expected results from the methods were twofold. First, a description of a possible trade of infected dog that enters the rabies-free zone. Thus, it can illustrate an illegal dog trade that adds a more complex situation to control rabies in the islands. Second, the expected results could identify the chain governance and its relation to a strong incentive for a dog trader to sell infected dog for profit. The expected conclusion from the method was the dog trade incentive may cause the rise of an outbreak in the free rabies zone area.
\end{abstract}

Keywords—outbreak, trade, dog, rabies, value chain, chain governance, consumers' behavior

\section{INTRODUCTION}

In early 2019, rabies outbreak in Dompu, West Nusa Tenggara killed five people and 527 people were bitten in the last six months. Since this area was declared as rabiesfree zone, it is suggested that there were many possible entrances of dogs by trading activities. The introduction of rabies into Dompu was caused by people's routine movement of dogs to Nusa Tenggara Islands. Since dogs were used for many activities, such as hunting, or guarding farm crops such as maize. Other source of introduction was suspected from traditional fishing activity from other endemic islands such as Bali dan East Nusa Tenggara (accompany by dogs) that landed in Nusa Tenggara Islands.

Dog movement is not the only cause of rabies outbreak. Many problems contributed in the introduction of rabies in Dompu, a regency previously free of the disease. First, number of dogs and rabies were not known. Second, many people were not familiar with rabies threat and danger. Third, lack of health responsibility from the dog owners. Fourth, the local government capacities on the animal health was limited to detect and respond to rabies. Lastly, the behavior of the people who did not immediately report to health posts once they got bitten was showing limited awareness and knowledge on rabies. These problems demonstrate the lack of knowledge of dog trades and movement in the region.

The rabies outbreak had direct and indirect impact on social wellbeing, and posed a major challenge for animal and human health in the region. Furthermore, the rabies outbreak forced the government to initiate restrictive policies and counter measures. The key elements to counteract a rabies threat are surveillance and diagnosis public awareness and capacity building, and vaccination. However, this approach to control rabies will not be effective, if the dog movement is not being controlled and the public awareness is low.

Policy makers should intervene to control the spread of rabies into the rabies-free region by using control mechanisms that address the economic and social aspects of dog movement and rabies impact. Nevertheless, a new policy has also to consider a cost effective control strategy that stimulate the owners and the actors in the dog trade to control rabies. Consequently, the development of an effective policy needs to understand the gods value chain and consumer behavior. Such an analysis allows the identification of key control points and important actors in the rabies outbreak.

There is no integrated analysis available with regard to the Indonesian dog value chain. However, limited information was provided on the governance structure of the rabies response in the dog value chain. Furthermore, there is no evidence on government intervention in the dog value chain. Therefore, our research will be based on value chain mapping and economic simulations of rabies control 
in the value chain. The objective of this paper was to propose a method to study a dog trade between islands that may contribute to a rabies outbreak. Following an interdisciplinary approach, the research combines business, consumers' social psychology and economic perspectives. Therefore, the research can guide policy makers to match rabies control with chain-level transactions. The research questions are:

1. How do the value chain features of dog trade channels in Nusa Tenggara Islands influence rabies control?

1. How do the value chain can be integrated with the rabies introduction?

2. What is the consumers' behavior towards rabies governance within various dog trade channels?

3. what are the dog utilities for possible cost-effective intervention strategies for rabies outbreak control in Nusa Tenggara Islands?

4. what types of incentive mechanisms can be used to control dog movement in the value chain?.

\section{METHODOLOGY}

The study will be carried out in the region Nusa Tenggara Islands. This is Indonesia's region that was free from rabies and suddenly hit by rabies outbreak. The details on data collection and methodologies employed are provided in Fig.1.

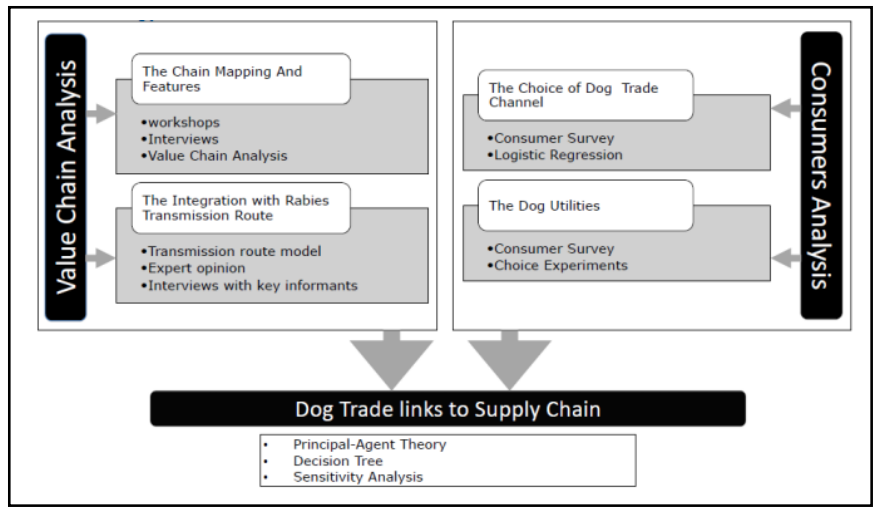

Fig. 1. The study framework of rabies assessment in Nusa Tenggara Islands

\section{A. The value chain analysis for dog trade}

This research will provide approaches how to assess the dog trading and its value chain to develop control of rabies. Since this research purposes to describe possible economic motives, consequently chain governance need to be understood. The main framework uses a Value Chain Analysis [1] to establish the dog trading in reaction to the chain governance and actors' behavior. Value chain analysis will structure the in-depth interview process and as an analytical tool for the results. The chain governance will be defined based on the dog trade activity to explain the transaction among actors. This study will assess the value chain features of dog trading in Nusa Tenggara Islands. The study will use Value Chain Analysis [1,2] to build a "tree" of input-output relationships of typical dog market characteristics. The Value Chain Analysis will be done in three stages: First, we will map the value chain to describe the nature of the relations between all actors to provide dogs in the market. Next, we will identify the governance structures. Finally, we will identify the economic impact of dog trade concerning the rabies outbreaks. Similar approach was used in different animal disease study by Indrawan, et al. [3].

\section{B. The integration of value chain with rabies transmission route}

We will use risk assessment as a foundation to integrate value chain with rabies transmission. As risk assessment is known as a systematic approach to identify and assess the probability of an unwanted incident and its follow-up consequences [4], it can be depicted on dog value chain map to outline the probabilities of rabies. The map will outline the diverse pathways of possible rabies introduction and transmission in the value chain.

Since we may come across insufficient detailed quantitative information on introduction and transmission in the dog trade for the value chain, we will employ a qualitative risk assessment. A qualitative assessment is frequently used to measure risk in the context of animal diseases [5-7]. It will use an opinion poll for the expertisebased assessment to measure: (i) the probability of rabies introduction or transmission for the defined pathways, and (ii) the uncertainty of the probabilities.

\section{The choice of dog trade channel}

This study will explore the dog trade channel based on the common usage of dogs in the region. We will use a framework which adapted from universal model of retail selection research $[8,9]$. The adapted model explore the relation of the consumer psychological factor, the consumer characteristics factor and the retail outlet features factor as independent factor to the choice of market channel. The questionnaire will be used to collect the data The first part will be on the consumer psychological factor. The second part is the consumer characteristics factor. The third part contains the retail outlet features. Then the variables will be used to analyze each characteristic effect in the logistic regression model of the channel choice and purchase behavior. Similar approach was used in different animal disease study by Indrawan, et al. [10].

\section{The measurement of dog utilities}

We will employ the choice experiment to examine dog utilities in this study. The approach is based on Lancaster consumer theory [11] that consumer choice (maximizing utility) is directed at mixtures of product attributes rather than goods. Then, we employed the random utility theory (RUT) to comprehends utility as the utility $U$ of an alternative can be called as the sum of observed and unobserved components [12]. A randomized choice-based conjoint (CBC) study design will be employed and we will perform a study that requires respondents to choose the attributes cmbination. We will design lists of attributes that are suitable to a local situation in Nusa Tenggara Islands for the randomized $\mathrm{CBC}$ research. The attributes and levels will be chosen based on initial interviews. Then we will calculate willingness to pay for dog trade attributes, while we used other attributes to examine the utility. 


\section{E. The measurement of incentive mechanism}

We will evaluate incentive mechanisms of rabies control in the dog value chain. In order to evaluate these proposed mechanisms, we will use the Principal Agent approach [13]. The models will explore an incentive system for evaluating the economic value of dogs. We will simulate types of incentive systems that influence dog trade actors' decisions on supply chain organization choices that optimizes their economic performance. The model will be using parameters based on information from scientific literature as well as information obtained from extensive interviews with supply chain actors and secondary data from the Government Agency.

\section{DISCUSSION}

In this proposed methods, we attempt to design research that examine the actors who are involve in the dog trade and their consumers. The study proposes the application of value chain as concept to describe a clear understanding of the organizational of the dog trade with regards to rabies outbreak and chain actors' responses. This approach will identify the actors that involve in trading and their economic motives. It will accomplish our main intention to examine the Nusa Tenggara Islands dog trade chain and its links to rabies control. The analyses will be described by a value chain map, an in-depth assessment of governance structures through different typologies of transactional dynamics and transaction cost economics, and a quantitative estimates of market power. Then the expected outcomes will be linked with a qualitative risk assessment of rabies introduction and transmission through expert knowledge elicitation. We believe these combined methods will give a foundation for control measures and government interventions.

As we also would like to understand the consumers from dog trade, we propose two research themes to examine consumers' choice and preference. The intention of consumers' choice of market channels to purchase dog trade is to describe the motive behind the consumers' preferences. Then by using a discrete choice experiment we try to explain consumers' choice of attributes of dog trade and the willingness to pay for these attributes. By using these approaches, it will support decision making process to prevent outbreak from rabies.

We believe that for the first time a value chain analysis will be applied to link trade with a rabies control in Indonesia. Differently from previous rabies studies based on epidemiology, a proper understanding of the organizational and institutional structure of the dog trade will be performed to match the government efforts to control rabies. Furthermore, the consumers' behavior studies are applied for the first time to explain consumer choice and preferences and circumstances of dog trade and rabies in Indonesia. These studies contributed to a novel knowledge of responds to disease risk in the value chain. Lastly, the study will be completed by the important of incentive mechanism for in government interventions. The key insights of incentive mechanism for chain actors and consumers will give a description of human behavior impacts and responds to disease risk. Then it will explain how to increase the voluntary action from chain actors to be involved in rabies control.

\section{CONCLUSION}

The expected results from the methods were twofold. First, a description of a possible trade of infected dog that enters the rabies-free zone. It can illustrate an illegal dog trade that adds a more complex situation to control rabies in the islands. Second, the expected results could identify the chain governance and its relation to a strong incentive for a dog trader to sell infected dog for profit. The expected conclusion from the method was the dog trade incentive may cause the rise of an outbreak in the free rabies zone area.

\section{REFERENCES}

[1] G. Gereffi, "A commodity chains framework for analyzing global industries," Institute of Development Studies, vol. 8, no. 12, pp. 1-9, 1999.

[2] T. Sturgeon, J. Van Biesebroeck, and G. Gereffi, "Value chains, networks and clusters: reframing the global automotive industry," Journal of economic geography, vol. 8, no. 3, pp. 297-321, 2008.

[3] D. Indrawan, K. M. Rich, P. van Horne, A. Daryanto, and H. Hogeveen, "Linking supply chain governance and biosecurity in the context of HPAI control in Western Java: a value chain perspective," Frontiers in veterinary science, vol. 5, 2018.

[4] S. Costard, G. Fournié, and D. U. Pfeiffer, "Using risk assessment as part of a systems approach to the control and prevention of HPAIV H5N1," EcoHealth, vol. 11, no. 1, pp. 36-43, 2014.

[5] S. Desvaux et al., "Risk of Introduction in $\mathrm{N}$ orthern V ietnam of HPAI Viruses from $\mathrm{C}$ hina: Description, Patterns and Drivers of Illegal Poultry Trade," Transboundary and emerging diseases, vol. 63, no. 4, pp. 389-397, 2016.

[6] L. Kelly, R. Kosmider, P. Gale, and E. Snary, "Qualitative import risk assessment: a proposed method for estimating the aggregated probability of entry of infection," Microbial Risk Analysis, vol. 9, pp. 33-37, 2018 .

[7] B. Wieland, S. Dhollander, M. Salman, and F. Koenen, "Qualitative risk assessment in a data-scarce environment: a model to assess the impact of control measures on spread of African Swine Fever," Preventive veterinary medicine, vol. 99, no. 1, pp. 4-14, 2011.

[8] Spiggle and M. A. Sewall, "A choice sets model of retail selection," Journal of Marketing, vol. 51, no. 2, pp. 97-111, 1987.

[9] R. Heider and S. Moeller, "Outlet patronage in on-the-go consumption: An analysis of patronage preference drivers for convenience outlets versus traditional retail outlets," Journal of retailing and consumer services, vol. 19, no. 3, pp. 313-324, 2012.

[10] D. Indrawan, G. Tacken, and H. Hogeveen, "What drives the choice of poultry market channel and the change of purchase behavior due to highly pathogenic avian influenza outbreaks?," Poultry science, vol. 97 , no. 10 , pp. 3652-3660, 2018.

[11] K. J. Lancaster, "A new approach to consumer theory," Journal of political economy, vol. 74, no. 2, pp. 132-157, 1966.

[12] D. McFadden, "Economic choices," American economic review, vol. 91, no. 3, pp. 351-378, 2001.

[13] J.-J. Laffont and D. Martimort, The theory of incentives: the principal-agent model. Princeton university press, 2009. 